\title{
Effect of dietary protein content on estrous behavior of dairy cows during early and mid lactation
}

\author{
R. A. Law, ${ }^{\star 1}$ F. J. Young, ${ }^{\star}$ D. C. Patterson, ${ }^{\star}$ D. J. Kilpatrick, $†$ A. R. G. Wylie, $†$ and C. S. Mayne ${ }^{\star}$ \\ ${ }^{*}$ Agri-Food and Biosciences Institute, Agriculture Branch, Hillsborough, County Down, Northern Ireland BT26 6DR \\ †Agri-Food and Biosciences Institute, Newforge Lane, Belfast, Northern Ireland BT9 5PX
}

\begin{abstract}
One of the main contributing factors to the decline in fertility in contemporary dairy farming is the inability to detect cows in estrus. In the current study, $90 \mathrm{Hol}-$ stein dairy cows [45 primiparous and 45 multiparous (mean parity of 3.1)] were allocated to 1 of 3 treatments at calving; 173,144 , or $114 \mathrm{~g}$ of crude protein $/ \mathrm{kg}$ of dry matter. Estrous behavior was recorded for one 30-min period every $12 \mathrm{~h}$ from calving until all animals reached $140 \mathrm{~d}$ postpartum. Behavioral activities were recorded according to a scoring system developed by Van Eerdenburg et al. (1996), with 9 key estrous behavioral activities each allocated a given number of points. If the total score allocated was greater than or equal to 50 points during a single or consecutive observational periods, then the animal was deemed to be in estrus. A total of 238 estrous cycles scored 50 points or above on the Van Eerdenburg et al. (1996) scale in this experiment, with $51.7 \%$ of these cycles being characterized as standing immobile on mounting. There were no direct effects of dietary protein content on estrous behavior; however, 3 significant stage of lactation $\times$ protein treatment interactions occurred for the behavioral activities (mucous discharge, chin resting, and mounting the head side of another cow), but no consistent trends were apparent from the predicted means. There was a significant influence of parity on the frequency of mounting the head side of another cow and total number of behavior activities displayed per estrous cycle. In both cases multiparous animals displayed fewer behavioral activities than primiparous animals. An increase in the size of the sexually active group (animals in estrus at the same time, up to 5) significantly increased the expression of mounting or attempting to mount another cow, the number of cycles in which standing immobile on being mounted was observed, the total estrous score and the proportion of cyclic animals that were diagnosed as being in estrus. The most frequent behavioral
\end{abstract}

Received March 14, 2008.

Accepted September 17, 2008.

${ }^{1}$ Corresponding author: Ryan.Law@afbini.gov.uk activity displayed was chin resting (89.5\% of cycles), and the most reliable behavior was standing immobile on mounting (when expressed $96.4 \%$ of cows were in estrus). The most dependable (function of reliability and frequency displayed) sign of estrus was mounting or attempting to mount another cow. This behavior was expressed in $83 \%$ of cycles, and when expressed, $89 \%$ of animals were in estrus.

Key words: estrous behavior, crude protein, mounting behavior, estrous detection

\section{INTRODUCTION}

Estrous detection is the most important managerial variable involved in reproductive performance (Van Vliet and Van Eerdenburg, 1996) and is one of the main contributing factors to the ongoing reproductive decline. Van Vliet and Van Eerdenburg (1996) referred to work by Heersche and Nebel (1994) stating that out of 4,550 herds in the United States, the mean estrous detection rate was 38\%. Coleman (1993) attributed $90 \%$ of low estrous detection rates to farm staff and $10 \%$ to the cow. Accurate estrous detection is not only important in maintaining short calving intervals but also in defining the time interval to insemination (Lyimo et al., 2000). Inaccurate detection of estrus may result in insemination of cows not in estrus or insemination at a time that is not optimal for conception. Van Eerdenburg et al. (2002) found that when ovulation occurred after $48 \mathrm{~h}$ postinsemination only $15 \%$ of the cows conceived, whereas $52 \%$ of cows that ovulated within $24 \mathrm{~h}$ of insemination conceived. Furthermore, Reimers et al. (1985) reported that $5.1 \%$ of cows were not in estrus when inseminated but emphasized that this percentage varied from 0 to $60 \%$ among herds. This could be due to early or late insemination or incorrect estrous detection. Additionally, it has been reported that 5 to $10 \%$ of pregnant cows also display some signs of estrus (Ambrose, 1999). With the introduction of estrous detection aids, farm staff may not be as vigilant on routine observations as they once were. The maintenance of a good level of knowledge of estrous symptoms and the observation of cows as frequently 
as possible, for a sufficient length of time, is critical for farm staff (Van Vliet and Van Eerdenburg, 1996). The duration and intensity of the displayed estrus is highly variable among individuals and is greatly influenced by the number of cows that are in estrus simultaneously (Diskin and Sreenan, 2000). Small groups of cows and all-year-round calving will greatly reduce the number of simultaneous estrous cycles.

In the present study the emphasis is on how nutrition, namely protein content of the diet, affects the expression of estrus. There is a common consensus that malnutrition or specific nutrient deficiencies may interfere with or inhibit estrous expression, or both; however, it is also considered that as long as cyclic ovarian function is proceeding normally, the expression of estrus will be unaffected (Allrich, 1993). It is thought that low dietary $\mathrm{CP}$ is associated with reduced estrous behavior and conception in beef heifers (Robinson, 1996). One possible explanation for this effect is the suggestion that decreased basal serum luteinizing hormone concentrations are associated with a decreased dietary CP intake, when compared with a greater CP intake (Westwood et al., 1998). Although luteinizing hormone is important in ovarian follicular development postcalving and estrous behavior (Ferguson, 1996; Westwood et al., 1998), there are suggestions that high protein diets can be detrimental to estrous expression (Orihuela, 2000). A greater dietary protein intake will increase milk yield, which is not emulated entirely by energy intake, subsequently exacerbating negative energy balance. This will inevitably increase the risk of prolonged anoestrus (Ferguson, 1991) due to poor follicular development, which will reduce estradiol production and subsequent expression of estrus. Spicer et al. (1990) found a positive correlation between energy balance and the frequency of visually observed estrus in the first postpartum ovulation. Ferguson (1996) also reported work from Harrison et al. (1990) suggesting that higher yielding cows will have less expression of estrus. Interestingly, Van Eerdenburg et al. (1998) reported that the estrous period was longer in animals with a more pronounced negative energy balance.

The objective of the present study was to evaluate the effect of level of dietary protein on the estrous behavior of high yielding dairy cows and the effectiveness of observing cows twice a day, for a duration of $30 \mathrm{~min}$, on estrous detection using a scoring system developed by Van Eerdenburg et al. (1996). It has been stated that the accuracy and efficiency of direct observation, as an estrous detection technique, is affected by the frequency, duration, and timing of the observation periods (Hurnik et al., 1975). However, with increasing herd sizes and reduced levels of staffing available on farms (Mayne, 2006), the manpower input per cow decreases
(Senger, 1994), which increases the need for more practical and focused estrous detection methods.

\section{MATERIALS AND METHODS}

\section{Animals and Housing}

Ninety Holstein dairy cows (45 primiparous and 45 multiparous; mean parity 3.1) were used in the experiment. Cows entered the trial following parturition ( $\mathrm{Au}-$ gust 29 to December 23). Following calving, animals were housed as a single unit in free stalls with concrete flooring. The cubicle to cow ratio was $\geq 1: 1$ at all times, meeting the recommendations set by FAWC (1997). All cubicles had a rubber mat bed measuring $2.20 \mathrm{~m}$ long and $1.25 \mathrm{~m}$ wide and were bedded with sawdust thrice weekly. Concrete passageway floors were scraped a minimum of 4 times daily, using an automated system. Cows were milked twice at 0530 and $1630 \mathrm{~h}$, with cows traveling about $35 \mathrm{~m}$ to the milking parlor. Lights were left on at all times.

\section{Experimental Design, Diets, and Feeding}

The experiment involved allocating 90 freshly calved Holstein-Friesian dairy cows to 3 dietary treatments that differed in overall CP levels, as formulated, in the complete diet (DM basis): 180, 150, and $120 \mathrm{~g} / \mathrm{kg}$ of DM. Primiparous animals were assigned in a balanced manner to treatments based on heifer rearing regime, calving date, and live weight. Multiparous animals were assigned to treatments according to parity, previous lactation milk yield, calving date, and live weight. The diet was presented as a TMR, and animals were fed between 1000 and 1100 h daily using a diet feeder. Animals had free access to water at all times. The concentrate to forage ratio (DM basis) was 0.55:0.45 for all diets. The forage component of the diet consisted of 0.60 grass silage and 0.40 maize silage (DM basis). Samples of grass and maize silage were taken weekly and analyzed using near infrared reflectance spectroscopy (Park et al., 1998) and twice weekly for measurement of nitrogen and ammonia nitrogen using methods outlined by Steen (1989). Two concentrates were formulated to contain 229 and $117 \mathrm{~g}$ of $\mathrm{CP} / \mathrm{kg}$ of $\mathrm{DM}$ to achieve target protein levels in the overall diets of 180 and $120 \mathrm{~g}$ of $\mathrm{CP} / \mathrm{kg}$ of $\mathrm{DM}$, respectively. Diets containing $150 \mathrm{~g}$ of $\mathrm{CP} / \mathrm{kg}$ of $\mathrm{DM}$ were produced by complementing the forage component with equal amounts of concentrates containing 117 and 229 $\mathrm{g}$ of $\mathrm{CP} / \mathrm{kg}$ of DM. The energy and protein concentrations of individual ingredients were based on published values (AFRC, 1993) and were used to formulate the concentrate proportion of the diet as presented in Table 1. Concentrate samples were taken weekly during the 
Table 1. Ingredient formulation of concentrates $(\mathrm{g} / \mathrm{kg}$ of fresh) and energy and protein concentration (as formulated)

\begin{tabular}{lcc}
\hline Item & Low protein & High protein \\
\hline & & \\
Barley & 240 & 140 \\
Wheat & 240 & 140 \\
Unmolassed sugar beat pulp & 163 & 94 \\
Citrus pulp & 163 & 94 \\
Maize gluten feed & 30 & 100 \\
Distillers grain & 80 & 100 \\
Soybean meal (Hi-Pro) & 0 & 165 \\
Rape meal & 0 & 100 \\
Megalac & 19 & 12.5 \\
Trace minerals and vitamins & 2.5 & 2.5 \\
Salt & 4 & 4 \\
Dicalcium phosphate & 10.5 & 0 \\
Limestone (CaCO & 13 & 13 \\
Magnesium oxide & 5 & 5 \\
Molasses & 30 & 30 \\
ME (MJ/kg of DM) & 13.1 & 13.1 \\
CP (g/kg of DM) & 116.6 & 228.6 \\
Effective RDP (g/kg of DM) & 78.5 & 134.8 \\
Digestible undegradable protein (g/kg of DM) & 28.9 & 73.5 \\
\hline
\end{tabular}

${ }^{1}$ Volac Ltd., Orwell, Hertfordshire, UK.

experiment and analyzed for DM, ash, ADF, NDF, and nitrogen as described by Cushnahan and Gordon (1995). The TMR diets were offered ad libitum using feed boxes that were placed on a computer recorded load cell system, with controlled access to the boxes using an electronic identification system. This enabled DMI of individual cows to be recorded continuously via automatic feeding gates (Calan gate feeder), from which a daily intake was calculated and then averaged on a weekly basis.

\section{Measurements}

In all animals, estrous behavior was recorded for one 30-min period every $12 \mathrm{~h}$ from calving until all animals had reached $140 \mathrm{~d}$ postpartum. During the observational period a trained observer walked through the herd examining animals for activity. All cows had identification collars and were freeze branded, allowing ease of identification. Behavioral activities were recorded according to a scoring system developed by Van Eerdenburg et al. (1996; Table 2), with 9 key estrous behavioral activities, each allocated a given number of points. Once each 30-min observational period was complete, the total number of points was calculated. If the total was greater than or equal to 50 points during a single observational period or consecutive (an aggregate score for a particular cycle) observational periods, then the animal was deemed to be in estrus (Van Eerdenburg et al., 1996). Technicians were trained to record estrous behavior over a 3 -wk period.
Milk yields were recorded daily at each milking throughout the experiment. Milk composition (fat, protein, lactose, and SCC) was determined on a weekly basis from one consecutive AM and PM milking. Separate analysis was completed for AM and PM samples, and milk composition was calculated on the basis of recorded AM and PM milk yields. Milk composition was determined using an infrared milk analyzer. Milk progesterone samples were collected twice weekly (Tuesday and Friday; AM milk samples) until pregnancy confirmation at d 30 postservice. Pregnancy was reconfirmed at $\mathrm{d} 60$ postinsemination, and in the event of embryo loss, milk progesterone samples commenced. Pregnancy was confirmed using an ultrasound scan carried out by a veterinarian. Milk progesterone concentrations were used to confirm ovulation and subsequently the validity of estrous expression. Milk progesterone concentrations

Table 2. Scoring scale for observed symptoms of estrus (Van Eerdenburg et al., 1996)

\begin{tabular}{lc}
\hline Symptoms of estrus & Score $^{1}$ \\
\hline Mucous vaginal discharge & 3 \\
Cajoling & 3 \\
Restlessness & 5 \\
Sniffing the vagina of other cow & 10 \\
Chin resting & 15 \\
Mounted but not standing & 10 \\
Mounting (or attempt) other cows & 35 \\
Mounting headside of other cow & 45 \\
Standing immobile on being mounted & 100 \\
\hline
\end{tabular}

${ }^{1}$ The symptoms are cumulative; once an observation is observed the allocated points are added to the total. 
Table 3. Production responses to dietary protein in early and mid-lactation (1 to $140 \mathrm{~d}$ )

\begin{tabular}{lcccccc}
\hline & \multicolumn{2}{c}{ Dietary CP concentration $(\mathrm{g} / \mathrm{kg}$ of DM) } & & \multicolumn{2}{c}{ Significance $^{1}$} \\
\cline { 2 - 3 } \cline { 6 - 7 } Item & 114 & 144 & 173 & & SED & $P$-value \\
\hline Milk yield $(\mathrm{kg} / \mathrm{d})$ & $25.4^{\mathrm{c}}$ & $31.8^{\mathrm{b}}$ & $35.5^{\mathrm{a}}$ & & 1.14 & $* * *$ \\
Dry matter intake $(\mathrm{kg} / \mathrm{d})$ & $164^{\mathrm{c}}$ & $18.0^{\mathrm{b}}$ & $18.5^{\mathrm{a}}$ & & 0.35 & $* * *$ \\
ME requirement $(\mathrm{MJ} / \mathrm{d})$ & $191^{\mathrm{c}}$ & $222^{\mathrm{b}}$ & $243^{\mathrm{a}}$ & & 6.35 & $* * *$ \\
ME intake (MJ/d) & $203^{\mathrm{b}}$ & $223^{\mathrm{a}}$ & $230^{\mathrm{a}}$ & & 4.53 & $* * *$ \\
Daily energy status (MJ/d) & $11.9^{\mathrm{a}}$ & $0.35^{\mathrm{a}}$ & $-12.7^{\mathrm{b}}$ & & 6.32 & $* *$ \\
Cumulative energy status (MJ) & $341^{\mathrm{a}}$ & $-568^{\mathrm{a}}$ & $-1,810^{\mathrm{b}}$ & & 502.2 & $* * *$ \\
\hline
\end{tabular}

${ }^{\mathrm{a}-\mathrm{c}}$ Means within a row with different superscripts differ significantly.

${ }^{1} \mathrm{SED}=$ standard error of the difference; ${ }^{* *} P<0.01 ;{ }^{* * *} P<0.001$.

were determined using an ELISA kit (Ridgeway Science Ltd., Lydney, UK) based on the method of Sauer et al. (1986). Sequential milk progesterone samples were plotted for each animal. If an animal was deemed to be in estrus and was past the voluntary waiting period $(42 \mathrm{~d})$, then she was presented for AI approximately $12 \mathrm{~h}$ after the observational period. In the absence of a continuous $(24 \mathrm{~h}$ ) observation of estrous activity, it is difficult to determine the exact time of onset of estrous activity. Reduced conception rates have been reported in cows inseminated $>16$ (Stevenson et al., 1984) and $>24$ h (Foote, 1979) after an observed estrus; therefore, a 12-h interval from estrus to AI was implemented. Insemination details were recorded (date, hour, sire, and inseminator).

Animals were blood sampled once weekly, between 0930 and $1130 \mathrm{~h}$, from the coccygeal vein using uncoated, heparin-coated, and fluoride oxalate coated tubes (BD, Oxford, UK) from calving until d 100 of lactation and then every 2 wk thereafter. Plasma was recovered by centrifugation for analysis of glucose, (fluoride oxalate tubes), total protein, albumin, globulin, BHBA, NEFA, and urea (heparinized tubes), respectively, by clinical analyzer (Olympus UK Ltd., Middlesex, UK). The NEFA concentrations were determined using a standard kit (Wako Chemicals GmbH, Neuss, Germany). Uncoated tubes provided serum for leptin radioimmunoassays. Plasma and serum samples were stored at $-20^{\circ} \mathrm{C}$ until analyzed. The radio-immunoassays were balanced for dietary treatments, and parity and control samples were included in each assay.

Serum leptin concentrations were determined in samples taken from all animals in each of wk 2, 4, 6, 8, 10, 12,16 , and 20 . The primary anti-leptin antibody (OL-3) was raised in guinea pigs using recombinant ovine leptin kindly donated by A. Gertler (The Hebrew University of Jerusalem) and was included at a final dilution of 1:160,000 in each assay. Primary antiserum $(100 \mu \mathrm{L})$ and plasma $(100 \mu \mathrm{L})$ were incubated overnight $(20 \mathrm{~h})$ in a refrigerator after which was added $100 \mu \mathrm{L}(12,000$ to $15,000 \mathrm{cpm}$ ) of ${ }^{125}$ I-iodinated ovine leptin, prepared using iodogen (Perbio Science, Northumberland, UK).
Tubes were then held for a further $24 \mathrm{~h}$ in a refrigerator before addition of $100 \mu \mathrm{L}$ of a cellulose-immobilized second antibody suspension (Sac-Cel anti-guinea pig IgG; IDS Ltd., Washington Tyne on Wear, UK). Tubes were then left at room temperature for 20 min before addition of $1 \mathrm{~mL}$ of deionized water and centrifugation at $1,900 \times g$ for $20 \mathrm{~min}$. Following centrifugation, supernatant was removed and radioactivity in each pellet was counted using a Cobra II gamma counter (Packard Canberra, Reading, UK).

Live weight and BCS (scale: 0 to 5; Edmonson et al., 1989) were recorded on a weekly basis throughout lactation. Locomotion scores were carried out every 2 wk using the method described by Manson and Leaver (1988).

\section{Calculation of Energy Balance}

The average daily energy balance for each animal was calculated each week of lactation using the equations described by Thomas (2004) $\{$ Energy balance $=\mathrm{ME}$ intake $-\mathrm{ME}$ requirement $\left[-10+\left(\mathrm{ME}_{\text {preg }}+\mathrm{ME}_{\text {maintmilk }}\right.\right.$ $\left.\left.\left.\times \mathrm{Lwt}^{0.75}\right)\right]+\left[(0.0013 \times \mathrm{Lwt}) / \mathrm{K}_{\mathrm{m}}\right]\right\}$. Daily milk yield, daily DMI, weekly milk composition, weekly live weight, and feed composition data were used in the calculations. The ME contents of grass and maize silage were obtained on a weekly basis using near infrared reflectance spectroscopy (Park et al., 1998), and ME contents of the concentrate were as formulated. Missing values were estimated from the week before and the week following missing data. Less than $2 \%$ of the data were missing.

\section{Statistical Analysis}

A repeated measures approach using the REML procedure available in GenStat (Payne et al., 1993) was used to analyze the data set. The model fitted fixed effects for parity, treatment, size of sexually active group, and stage of lactation ( 0 to $20 \mathrm{wk}$ ). The model included all 2-level interactions between these variables. Two covariates were used in the analysis of 
the data; the deviation from the mean condition score of multi- and primiparous animals during the first 3 wk of lactation and the deviation from the mean of the first 2 locomotion scores recorded of multi- and primiparous animals. There was no significant effect of treatment on the change in condition score in the first 3 wk of lactation or on the difference between the first 2 locomotion scores recorded, therefore allowing them to be used as covariates.

Regression analysis was performed for several additional independent variables on all the behavioral activities (response variables). In this analysis the fitted terms included; constant + parity + stage of lactation + an additional variable $(\mathrm{X})$. These additional independent variables included the blood constituents: leptin, urea, globulin, albumin, total protein, BHBA, NEFA, and glucose.

\section{RESULTS}

\section{Production Responses to Dietary Protein in Early and Mid-Lactation (1 to 140 d)}

The composition (as fed) of diets targeted to contain 120,150 , and $180 \mathrm{~g}$ of $\mathrm{CP} / \mathrm{kg}$ of $\mathrm{DM}$ were 114,144 , and $173 \mathrm{~g}$ of $\mathrm{CP} / \mathrm{kg}$ of $\mathrm{DM}$, respectively. All diets were isoenergetic. Dietary protein concentration effects on milk yield, DMI, ME requirement, ME intake, daily energy balance and cumulative energy balance are presented in Table 3. Increased dietary protein concentration significantly $(P<0.001)$ increased milk yield, DMI, and ME requirement. Increasing dietary protein concentration from 114 to $144 / 173 \mathrm{~g} / \mathrm{kg}$ of DM significantly $(P<$ 0.001) increased ME intake. Increasing dietary $\mathrm{CP}$ concentration from 114/144 to 173 significantly decreased daily energy balance and cumulative energy balance.

\section{Behavioral Trends}

Examination of the progesterone profiles of the group of 90 animals indicated that 367 estrous cycles occurred during the 140-d period postcalving. Of these 367 cycles, 72 were described as being silent, defined as an animal not being observed in estrus by the trained dairy technicians during an observational period or by the farm staff who carried out four 20-min observational periods during each 24-h period $(0800,1200,1600$, and 2100 $\mathrm{h}$, with additional observations during collection). The highest percentage (47.2) of silent estrous cycles were displayed in the first cycle and decreased thereafter. Interestingly, in their fourth and fifth estrous cycles, 4 animals failed to display estrous activity. In $65 \%$ of ovulations, a cumulative estrous behavior score of 50 points or more was observed by dairy technicians dur- ing the 30-min observational period carried out at 12 -h intervals. In $7.6 \%$ of ovulations, behavioral activity was observed, but the cumulative total score was below 50 points, which signifies a nonestrous state, according to the behavioral scoring system. In a further $7.9 \%$ of ovulations, behavioral indicators of estrus were detected by farm staff on their routine observations but not by dairy technicians during the experimental observational periods. An additional 34 positive estrous cycles (a score of 50 or above) were recorded in animals considered to be acyclic based on their progesterone profiles, and of these, 8 positive estrous cycles ( 7 different animals) were recorded in pregnant animals. Furthermore, on 63 occasions, estrous behavioral activity with a score below 50 occurred in animals that were considered to be acyclic from their progesterone profiles.

The mean number of individual behavioral activities recorded across all cycles was 20.9 per cycle (SED $=0.86$ ), with a maximum and minimum of 72 and 3, respectively. The mean estrous behavior score was 421 $(\mathrm{SED}=19.1)$ per cycle, with a maximum and minimum of 1,480 and 52, respectively. Estrous behavior score had no significant effect $(P>0.05)$ on conception rate; however, animals that conceived tended to have a higher estrous behavior score than animals that failed to conceive ( 475 vs. 396 , respectively; $\mathrm{SED}=48.0$ ). The reliability of each behavioral activity as an indicator of estrus, the percentage expression, and the average frequency of each behavioral activity are presented in Table 4, based on analysis of progesterone profiles. The most reliable behavioral activity in detecting estrus was standing immobile on being mounted (when expressed, $96.4 \%$ of animals were in estrus). The least reliable and the least frequently displayed (per cycle) behavioral activity was mucous vaginal discharge (when expressed, $75.7 \%$ of animals were in estrus; 0.11 occurrences per estrous cycle). The most frequently displayed behavioral activity was chin resting (5.68 times per estrous cycle). The behavioral activity expressed in the highest number of cycles was chin resting $(89.5 \%)$. Standing immobile on being mounted was expressed in $51.7 \%$ of the cycles. During the first ovulation, only $23 \%$ of animals displaying estrous behavior stood immobile on being mounted (11\% of all animals). During the second ovulation $52 \%$ of animals displaying estrous behavior stood immobile on being mounted (36\% of all animals). There was no effect of cycle number on the intensity of the estrous behavior displayed.

\section{Effect of Treatment, Parity, and the Size of the Sexually Active Group}

The REML variance component analysis indicates that there was no significant $(P>0.05)$ direct effect 
Table 4. Analysis of estrous cycles with a cumulative estrous behavior score of 50 points or more $(\mathrm{n}=238)$

\begin{tabular}{lccc}
\hline Estrous behavior & $\begin{array}{c}\text { Reliability of } \\
\text { behavioral activity }\end{array}$ & $\begin{array}{c}\text { Percentage } \\
\text { expression }^{2}\end{array}$ & \begin{tabular}{c} 
Average counts $^{\text {per cycle }^{3}}$ \\
\hline Mucous vaginal discharge
\end{tabular} \\
Cajoling & 75.7 & 8.8 & 0.11 \\
Restlessness & 76.9 & 53.4 & 1.44 \\
Sniff the vagina of other cow & 78.9 & 81.5 & 3.22 \\
Chin resting & 80.5 & 86.6 & 5.37 \\
Mounted but not standing & 78.3 & 89.5 & 5.68 \\
Mounting (or attempt) other cows & 88.5 & 19.7 & 0.40 \\
Mounting head side of other cows & 95.0 & 22.3 & 2.88 \\
Standing immobile on & 96.4 & 51.7 & 0.41 \\
being mounted & & & 1.38 \\
\hline
\end{tabular}

${ }^{1}$ Percentage of animals that expressed this behavior and were in estrus based on progesterone profile.

${ }^{2}$ Percentage of estrous cycles in which behavior was expressed.

${ }^{3}$ Number of times each behavioral activity was expressed in the average cycle. The average cycle included 20.9 individual behavioral activities.

of dietary protein concentration on any of the estrous behaviors. However, the predicted means suggest that there is a tendency for reduced dietary protein content to increase estrous behavioral score. Diets containing 173,144 , and $114 \mathrm{~g}$ of $\mathrm{CP} / \mathrm{kg}$ of $\mathrm{DM}$ had mean estrous behavior scores of 328, 357, and 404 (SED, 55.7), respectively. Three significant stage of lactation $\times$ protein treatment interactions were found for the behavioral activities; mucous vaginal discharge $(P<0.01)$, chin resting $(P<0.01)$, and mounting the head side of a cow $(P<0.05)$, but no consistent trends from the predicted means were apparent. Significant effects of parity were also realized. Compared with multiparous animals, primiparous animals displayed significantly more mounting the head side of another cow (0.41 vs. 0.16 ; SED $=0.09$ ) per cycle and displayed a significantly greater total number of behavioral activities per cycle (22.4 vs. 18.7 ; SED $=1.75)$. There was no significant $(P>0.05)$ effect of parity on the number of silent estrous cycles.

The size of the sexually active group had a significant effect on the expression of mounting or attempting to mount another cow $(P<0.05)$, standing immobile on being mounted $(P<0.001)$, and the total estrous score obtained $(P<0.001$; Table 5$)$. There was a positive correlation between the number of animals in a sexually active group (up to 5) and the above behavioral variables. The number of occasions in which a sexually active group size was observed decreased with an increase in the size of the sexually active group. Also, the size of the sexually active group had a significant effect on whether or not animals that were cycling (according to the progesterone profiles) were actually detected during the 30-min observational period $(P<$ 0.001). The larger the sexually active group the higher the proportion of cows that were correctly diagnosed as being in estrus $(0.59,0.91,0.91,0.94,0.96$, and 0.99 for a sexually active group size of $1,2,3,4,5$, and 6 , respectively; SED $=0.07)$. There was no significant $(P$ $>0.05$ ) effect of dietary protein concentration or stage of lactation on the size of the sexually active group.

\section{The Effect of Blood Variables on Behavioral Activities}

Effects of blood variables on the expression of estrous behavioral activities are presented in Table 6 . The total behavioral score was significantly affected by plasma urea $(P<0.05$; negative relationship). An increase in serum leptin concentrations significantly increased the expression of cajoling $(P<0.01)$ and the expression of mounting the head side of another cow $(P<0.01)$. An increase in globulin and total protein significantly $(P<$ $0.05)$ decreased the expression of restless behavior.

\section{DISCUSSION}

\section{Behavioral Trends}

In the current experiment, an estrous detection rate of $65 \%$ was achieved when cows were observed for two 30 -min periods (12-h interval) every $24 \mathrm{~h}$. The farm staff, who have a standard operating procedure for estrous detection, realized a marginally higher $(73 \%)$ detection rate by observing the animals during four 20-min observational periods per 24 -h period, with additional observations during the milking periods. These estrous detection rates are similar to those reported by Van Eerdenburg et al. (1996), who stated that 2 observational periods of 30-min duration per 24-h period could achieve a $74 \%$ detection rate. Van Vliet and Van Eerdenburg (1996) also noted that a decrease in the duration of the observational period from 30 to $20 \mathrm{~min}$ would decrease the detection rate by $20 \%$. 
Table 5. Effect of the size of the sexually active group on the expression of estrous behaviors (following a square root transformation)

\begin{tabular}{|c|c|c|c|c|c|c|c|c|}
\hline \multirow{2}{*}{$\begin{array}{l}\text { Behavioral } \\
\text { activity }^{1}\end{array}$} & \multicolumn{6}{|c|}{ Size of sexually active group ${ }^{2}$} & \multirow[b]{2}{*}{$\mathrm{SED}^{3}$} & \multirow[b]{2}{*}{ Significance } \\
\hline & 1 & 2 & 3 & 4 & 5 & 6 & & \\
\hline Occurrences ${ }^{4}$ & 49 & 41 & 31 & 24 & 7 & 6 & 0.078 & \\
\hline Mounting & 1.11 & 1.27 & 1.38 & 1.47 & 1.70 & 1.66 & 0.228 & * \\
\hline Standing & 0.19 & 0.48 & 0.76 & 1.04 & 1.14 & 0.94 & 0.212 & $* * *$ \\
\hline Total & 15.7 & 17.1 & 18.8 & 20.1 & 22.1 & 20.2 & 1.735 & $* * *$ \\
\hline
\end{tabular}

${ }^{1}$ Mounting $=$ mounting or attempting to mount another cow; Standing $=$ standing immobile on being mounted; Total $=$ total estrous score

${ }^{2}$ Size of sexually active group, number of cows that displayed interactive estrous behavior during an observational period.

${ }^{3} \mathrm{SED}=$ standard error of the difference; $* P<0.05 ; * * * P<0.001$.

${ }^{4}$ Occurrences $=$ the number of occasions a sexually active group of this size was observed.

Silent ovulations are another common problem associated with estrous detection and are thought to be widespread among high-yielding dairy cows (Shipka, 2000). The absence of estrous behavior before the first ovulation is normally attributed to an excessively high concentration of estradiol at the end of pregnancy, which elicits a refractory state in the hypothalamus (Allrich, 1994). It has been suggested that the release of progesterone during the first postpartum luteal phase alleviates this refractory state and allows the cow to express estrus when the normal rise in concentration of estradiol occurs during the second ovulation (Kyle et al., 1992; Allrich, 1994). King et al. (1976) and Kyle et al. (1992) indicated that 50 to $80 \%$ of first ovulations are silent, but that by the third ovulation $100 \%$ of cows will exhibit estrous behavior. In the current study $19.6 \%$ of all cycles and $47.2 \%$ of first ovulations were silent. These results are similar to those quoted by Shipka (2000), who stated that $22 \%$ of all cycles were silent, with $42.1 \%$ of first ovulations being silent. The findings of the present study also suggest that silent estrus may also occur in later cycles (cycles 4 and 5). Gil et al. (1997) stated that $48 \%$ of animals displayed at least one silent estrous cycle before becoming pregnant whereas in the current experiment this was found to be the case in $59 \%$ of animals. In the present study a silent estrous cycle was defined as an animal not being observed in estrus by the trained dairy technicians during an ob- servational period or by the farm staff on their routine observations. However, it must be emphasized that this does not mean that the cow did not display any signs of estrus. Some cows in estrus do not arouse the interest of others (Ball and Jackson, 1979), which may limit the external signs of estrus. Additionally, with the duration of estrus being reported to be as low as $4 \mathrm{~h}$ (Van Vliet and Van Eerdenburg, 1996), a short estrous cycle could be missed between observational periods.

Standing immobile on being mounted is recognized as the primary and most reliable sign of estrus and the best indicator of the cow's preovulatory state (Hafez et al., 1969). In this study it was found that $96 \%$ of cows standing immobile on being mounted were in estrus. However, not all animals will stand to be mounted during estrus (Foote, 1974; Pennington et al., 1986; Kerbrat and Disenhaus, 2004). Historically, relatively high percentages of standing immobile on being mounted have been quoted in the literature. Trimberger and Fincher (1956) reported that by d 90 postcalving $93 \%$ of cows displayed this behavior. Similarly, Hurnik (1987) reported that over $70 \%$ of animals in estrus stood immobile on being mounted. However, more recently the expression of standing immobile on being mounted has been reported to be as low as $37 \%$ (of cycles) when cows are in estrus (Van Vliet and Van Eerdenburg, 1996). The latter authors observed animals for $30 \mathrm{~min}$ every $2 \mathrm{~h}$ for a 6 -wk period. In the present study the

Table 6. Effect of blood variables on the expression of estrous behaviors (regression analysis)

\begin{tabular}{lllcc}
\hline Blood variable & Estrous behavior & Relationship & Significance $^{1}$ & $\mathrm{r}^{2}$ \\
\hline Urea & Total behavior score & Negative & $*$ & 0.02 \\
Leptin & Cajoling & Positive & $* *$ & 0.04 \\
Leptin & Mounting head side of another cow & Positive & $* *$ & 0.03 \\
Globulin & Restlessness & Negative & $*$ & 0.02 \\
Total protein & Restlessness & Negative & $*$ & 0.02 \\
\hline
\end{tabular}

${ }^{1}$ Significance: ${ }^{*} P<0.05 ; * * P<0.01$. 
Table 7. The dependability of estrous behavioral activities, as a function of reliability and percentage expression, in identifying cows in a preovulatory state

\begin{tabular}{lccc}
\hline Estrous behavior & Reliability $^{1}$ & $\begin{array}{c}\text { Percentage }^{2} \\
\text { expression }^{2}\end{array}$ & Dependability $^{3}$ \\
\hline Mucous vaginal discharge & 75.7 & 8.8 & 667 \\
Cajoling & 86.9 & 53.4 & 4,640 \\
Restlessness & 78.9 & 81.5 & 6,430 \\
Sniffing the vagina of other cow & 75.8 & 86.6 & 6,564 \\
Chin resting & 80.5 & 89.5 & 7,205 \\
Mounted but not standing & 78.3 & 19.7 & 1,543 \\
Mounting (or attempt) other cows & 88.5 & 83.2 & 7,363 \\
Mounting head side of other cow & 95.0 & 22.3 & 2,119 \\
Standing immobile on being mounted & 96.4 & 51.7 & 4,984 \\
\hline
\end{tabular}

${ }^{1}$ Percentage of animals that expressed this behavior and were in estrus based on progesterone profile.

${ }^{2}$ Percentage of estrous cycles in which behavior was expressed.

${ }^{3}$ Function; reliability $\times$ percentage expression.

animals were observed for one 30-min period every 12 h. Standing immobile on being mounted was expressed in $51.7 \%$ of cycles; however, during the first and second cycle it was only expressed in 11 and $36 \%$ of animals, respectively. On average, standing to be mounted represented only $6.7 \%$ of the total behavior recorded, which is comparable to the $8 \%$ reported by Kerbrat and Disenhaus (2004). However, Senger (1994) referred to earlier work stating that standing immobile on being mounted represents less than $1 \%$ of the period of estrus (Senger, 1990) and is thus exceptionally difficult to detect without significant devotion to direct observations. Therefore, the use of secondary behavioral activities in the accurate identification of estrous expression is vital. The most frequently displayed behavioral activities in this experiment were chin resting, sniffing the vagina of another cow, and mounting, or attempting to mount, another cow. Although these behaviors are not as reliable as standing immobile on being mounted, they occur more often, which makes them extremely useful. It is suggested that an overall dependability score would be the best method of assessing how useful a behavior is in detecting estrus. This score would be a function of reliability and percentage expression. Table 7 illustrates a dependability score for the behavioral activities observed in this experiment. This approach would suggest that standing immobile on being mounted is only the fifth most dependable estrous behavior in identifying cows that are in the preovulatory stage of the estrous cycle. Interestingly, mounting or attempting to mount another cow is characterized as the most dependable sign of estrus. Mounting or attempting to mount another cow was observed in $83 \%$ of estrous cycles, and when expressed, $89 \%$ of cows were in estrus. Despite being highly reliable (when expressed, 96\% of cows were in estrus), standing immobile on being mounted was only expressed in $51.7 \%$ of estrous cycles.

\section{Effects of Treatment, Parity, and Size of Sexually Active Group}

There was no significant effect of dietary protein concentration of the expression of estrous behavioral activities. It was hypothesized that animals receiving a high concentration of dietary crude protein would have increased milk yields and subsequently a more negative energy balance. Potentially, this would reduce estradiol production and subsequent estrous expression. Lyimo et al. (2000) stated that maximum estradiol concentrations correlated with total estrous score. Despite the dramatic effect of dietary protein concentration on milk output and subsequent energy status, no direct influences of dietary protein concentration were realized in the current study. Harrison et al. (1990) reported that higher yielding cows had a lower expression of estrus; however, milk yield differences were a response to genetic merit as opposed to nutrition.

There was a significant influence of parity on the frequency of mounting head side of another cow and total number of behavior activities displayed per cycle. In both cases, multiparous animals displayed fewer behavioral activities than primiparous animals. In contrast, Van Vliet and Van Eerdenburg (1996) reported that multiparous animals displayed significantly more intense cycles than primiparous animals with respective estrous scores of 578 and 361, and this trend was also reported by Gwazdauskas et al. (1980). However, in the present experiment there was no significant difference between multi- and primiparous animals for the overall behavioral score (intensity of behavior). In a review, Orihuela (2000) reported that younger cows display fewer silent estrous cycles than older cows; however, this was not proven in the present study.

In this study, artificial synchronization of estrus was not implemented (however, reproductive intervention 
may have influenced synchronization patterns), which allowed the natural synchronization of estrus, reflected in the formation of sexually active groups. Natural synchronization will be influenced by group size, calving pattern, and group composition (Hurnik, 1987). The findings of previous experiments have shown that maximum expression of estrous behavior (average mounts per cow) occurs when 3 cows are in estrus simultaneously (Hurnik et al., 1975). In the current study behavioral expression was displayed at a maximum when 5 cows were in estrus simultaneously. However, the number of occasions in which 5 animals were in estrus simultaneously was one-seventh of that observed when only one animal was in estrus ( 7 vs. 49). When only one animal is in estrus, mounting activity and the duration of estrus is minimal (Hurnik and King, 1987). Small groups and all-year-round calving will greatly reduce the number of simultaneous estrous cycles, subsequently reducing the expression of estrus. A close calving pattern will increase the probability of natural synchronization or clustering of cows displaying estrous behavior within the herd due to social facilitation and sexual stimulation (Kilgour et al., 1977). Hurnik et al. (1975) found that the number of mounts increased from 11.2 to 52.6 when the number of cows in estrus increased from 1 to 3 . In the present study the number of mounts per cycle (during the observational periods) increased from 0.11 to 2.4 when the size of the sexually active group increased from 1 to 5 cows. Experimental examples of this social influence have also been reported in a review by Orihuela (2000), demonstrating the effect of synergy in the expression of estrous behavior due to the presence of companion cows. Orihuela (2000) stated that natural synchronization of estrous behavior indicates the effect of sensory stimulation within a group and its influence on the activity of neurohormonal mechanisms in controlling sexual behavior. Hurnik (1987) stated that pheromones (i.e., biochemical substances dispersed into an animal's external environment) can induce physiological changes when received by other individuals of the same species.

\section{CONCLUSIONS}

Low rates of estrous detection are a major problem on commercial dairy farms due to increases in herd size, reduced staffing levels, and effects of housing and feeding (Mayne, 2006). Any adjustment in procedures to improve the success of the detection of estrus will also potentially improve fertility. The experimental protocol implemented for observation and recording of estrous behavior, of two 30 -min periods per 24 -h period, would appear to be relatively successful (65\% detection rate), and in conjunction with estrous detection during collection for milking, could be a viable approach to estrous detection in modern dairy herds. Silent estrous expression is a major problem in detecting estrus in cyclic cows, with $19.6 \%$ of estrous cycles being recorded as silent in the present study. Standing immobile on being mounted is the most reliable indicator of estrus; however, when used exclusively in estrous detection, the low frequency of expression makes it less useful. The additional use of secondary behaviors (namely, mounting or attempting to mount another cow, sniffing the vagina of another cow, and chin resting) are crucial in increasing the efficiency of estrous detection. Using these behaviors proved to be valuable in accurate estrous detection. The size of the sexually active group had a major effect on the intensity of the estrous expressed. Therefore, large groups of animals and concentrated calving patterns will increase the likelihood of natural synchronization of estrus and improve the probability of accurate estrous detection. There was no direct effect of dietary protein content on the expression of estrous behavior in the current study.

\section{ACKNOWLEDGMENTS}

Thanks are due to the technical staff at AFBI Agriculture Branch, Hillsborough, for their assistance in recording and preparing data sets. Assistance with analysis of blood samples at the Veterinary Sciences Division is greatly acknowledged. This study was cofunded by the Department of Agriculture and Rural Development and AgriSearch.

\section{REFERENCES}

Agricultural and Food Research Council (AFRC). 1993. Energy and protein requirements of ruminants. CAB Int., Wallingford, UK.

Allrich, R. D. 1993. Estrous behavior and detection in cattle. Vet. Clin. North Am. 9:249-262.

Allrich, R. D. 1994. Endocrine and neural control of estrus in dairy cows. J. Dairy Sci. 77:2738-2744.

Ambrose, D. J. 1999. An overview of strategies to improve reproductive efficiency. Advances Dairy Technol. 11:87-106.

Ball, P. J. H., and N. W. Jackson. 1979. The fertility of dairy cows inseminated on the basis of milk progesterone measurements. Br. Vet. J. $135: 537-540$.

Coleman, D. A. 1993. Detecting estrus in dairy cattle. USA National Dairy Database, Reprod. Collection, Univ. Maryland, College Park. http://www.inform.umd.edu/EdRes/Topic/AgrEnv/ndd/ reproduc/

Cushnahan, A., and F. J. Gordon. 1995. The effects of grass preservation on intake, digestibility and rumen degradation characteristics. Anim. Sci. 60:429-438.

Diskin, M. G., and J. M. Sreenan. 2000. Expression and detection of oestrous in cattle. Reprod. Nutr. Dev. 40:481-491.

Edmonson, A. J., I. J. Lean, L. D. Weaver, T. Farver, and G. Webster. 1989. A body condition scoring chart for Holstein dairy cows. J. Dairy Sci. 72:68-78.

Farm Animal Welfare Council (FAWC). 1997. Report on the Welfare of Dairy Cattle. FAWC, Surrey, UK.

Ferguson, J. D. 1991. Nutrition and reproduction in dairy cows. Vet. Clin. North Am. 7:483-507. 
Ferguson, J. D. 1996. Diet, production and reproduction in dairy cows. Anim. Feed Sci. Technol. 59:173-184.

Foote, R. H. 1974. Estrus detection and estrus detection aids. J. Dairy Sci. 58:248-256.

Foote, R. H. 1979. Time of artificial insemination and fertility in dairy cattle. J. Dairy Sci. 62:355-358.

Gil, Z., J. Szarek, and J. Kural. 1997. Detection of silent oestrous in dairy cows by milk temperature measurement. Anim. Sci. 65:2529 .

Gwazdauskas, F. C., J. A. Lineweaver, and M. L. Mcgilliard. 1980. Management and environment influences on estral activity in dairy cattle. J. Anim. Sci. 51:107 (Abstr.)

Hafez, E. S. E., M. W. Shein, and R. Ewbank. 1969. The behaviour of cattle. Pages 235-295 in The Behaviour of Domestic Animals. 2nd ed. E. S. E. Hafez, ed., Williams and Wilkins, Baltimore, MD.

Harrison, R. O., S. P. Ford, J. M. Young, A. J. Conley, and A. E. Freeman. 1990. Increased milk production versus reproductive and energy status of high producing dairy cows. J. Dairy Sci. 73:2749-2758.

Heersche, G., and R. L. Nebel. 1994. Measuring efficiency and accuracy of detection of oestrus. J. Dairy Sci. 77:2754-2761.

Hurnik, J. F. 1987. Sexual-behaviour of female domestic mammals. Vet. Clin. North Am. Food Anim. Pract. 3:423-462.

Hurnik, J. F., and G. J. King. 1987. Oestrous behaviour in confined beef cows. J. Anim. Sci. 65:431-438.

Hurnik, J. F., G. J. King, and H. A. Robertson. 1975. Oestrus and related behaviour in postpartum Holstein cows. Appl. Anim. Ethol. 2:55-58.

Kerbrat, S., and C. Disenhaus. 2004. A proposition for an updated behavioural characterization of the oestrous period in dairy cows. Appl. Anim. Behav. Sci. 87:223-238.

Kilgour, R., B. H. Skarscholt, J. F. Smith, K. J. Bremner, and M. C. L. Morrison. 1977. Observation of the behaviour and factors influencing the sexually active group in cattle. Proc. N. Z. Soc. Anim. Sci. 37:128-135.

King, G. J., J. F. Hurnik, and H. A. Robertson. 1976. Ovarian function and oesrus in dairy cows during early lactation. J. Anim. Sci. 42:688-692.

Kyle, S. D., C. J. Callahan, and R. D. Allrich. 1992. Effect of progesterone on the expression of estrus at the first post partum ovulation in dairy cattle. J. Dairy Sci. 75:1456-1460.

Lyimo, Z. C., M. Nielen, W. Ouweltjes, T. A. M. Kruip, and F. J. C. M. Van Eerdenburg. 2000. Relationship among estradiol, cortisol and intensity of estrous behavior in dairy cattle. Theriogenology $53: 1783-1795$

Manson, F. J., and J. D. Leaver. 1988. The influence of concentrate amount on locomotion and clinical lameness in dairy cattle. Anim. Prod. 47:185-190.

Mayne, C. S. 2006. Effects of nutrition and other management factors on oestrus detection in high yielding dairy cows. Pages 25-29 in Proc. Nottingham Cattle Fertility Conf. The University of Nottingham, Br. Cattle Vet. Assoc.

Orihuela, A. 2000. Some factors affecting the behavioural manifestation of oestrous in cattle: A review. Appl. Anim. Behav. Sci. 70:1-16.

Park, R. S., R. E. Agnew, F. J. Gordon, and R. W. J. Steen. 1998. The use of near infrared reflectance spectroscopy (NIRS) on undried samples of grass silage to predict chemical composition and digestibility parameters. Anim. Feed Sci. Technol. 72:155-167.

Payne, R. W., P. W. Lane, P. G. N. Digby, S. A. Harding, P. K. Leech, G. W. Morgan, A. D. Todd, R. Thompson, G. Tunnicliffe
Wilson, S. J. Welham, and R. P. White. 1993. GenStat 5 Release 3 Reference Manual. Oxford Science Publications.

Pennington, J. A., J. L. Albright, and C. J. Callahan. 1986. Relationship of sexual activities in estrous cows to different frequencies of observation and pedometer measurements. J. Dairy Sci. 69:29252934.

Reimers, T. J., R. D. Smith, and S. K. Newman. 1985. Management factors affecting reproductive performance of dairy cows in the northeast United States. J. Dairy Sci. 68:963-977.

Robinson, D. L. 1996. Nutrition and reproduction. Anim. Reprod Sci. $42: 25-34$

Sauer, M. J., J. A. Foulkes, A. Worsfold, and B. A. Morris. 1986. Use of progesterone 11-glucuronide-alkaline phosphatise conjugate in a sensitive microtitre-plate enzyme-immunoassay of progesterone in milk and its application to pregnancy testing in dairy cattle. J. Reprod. Fertil. 76:375-391.

Senger, L. 1990. Heat detection-Some little known facts and problems. Some possible solutions. Page 196 in Proc. Lower Columbia and North West Dairy Shortcourse. Washington State Univ., Pullman.

Senger, P. L. 1994. The estrus detection problem: New concepts, technologies and possibilities. J. Dairy Sci. 77:2745-2753.

Shipka, M. P. 2000. A note on silent ovulation identified by using radiotelemetry for estrous detection. Appl. Anim. Behav. Sci 66:153-159.

Spicer, L. J., W. B. Tucker, and G. D. Adams. 1990. Insulin-Like growth factor-1 in dairy cows: Relationships among energy balance, body condition, ovarian activity and estrous behaviour. J. Dairy Sci. 73:929-937.

Steen, R. W. J. 1989. A comparison of soyabean, sunflower, and fish meals as protein supplements for yearling cattle offered grass silage based diets. Anim. Prod. 48:127-132.

Stevenson, J. S., M. K. Schmidt, and E. P. Call. 1984. Gonadotropinreleasing hormone and conception of Holsteins. J. Dairy Sci. $67: 140-145$.

Thomas, C. 2004. Feed into Milk: An Advisory Manual. Nottingham University Press, Nottingham, UK.

Trimberger, G. W., and M. G. Fincher. 1956. Regularity of oestrus, ovarian function, and conception rates in dairy cattle. Cornell Univ. Agric. Sta. Bull. 911.

Van Eerdenburg, F. J. C. M., D. Karthaus, M. A. M. Tavern, I Merics, and O. Szenci. 2002. The relationship between estrous behavioral score and time of ovulation in dairy cattle. J. Dairy Sci. 85:1150-1156.

Van Eerdenburg, F. J. C. M., B. Landman, T. Wensing, and T. A M. Kruip. 1998. Influence of dry cow management on oestrous expression in dairy cows. Page 195 in Proc. 10th Int. Conf. Prod. Dis. Farm Anim., Utrecht, the Netherlands. T. Wensing, ed. Wageningen Press, Wageningen, the Netherlands.

Van Eerdenburg, F. J. C. M., H. S. H. Loeffler, and J. H. Van Vliet. 1996. Detection of estrus in dairy cows: A new approach to an old problem. Vet. Q. 18:52-54.

Van Vliet, J. H., and F. J. C. M. Van Eerdenburg. 1996. Sexual activities and oestrous detection in lactating Holstein cows. Appl. Anim. Behav. Sci. 50:57-69.

Westwood, C. T., I. J. Lean, and R. C. Kellaway. 1998. Indications and implications for testing milk urea in dairy cattle: A quantitative review Part 2. Effect of dietary protein on reproductive performance. N. Z. Vet. J. 46:123-130. 